\title{
СТАНОВЛЕНИЕ СИСТЕМЫ СОВЕТСКИХ МАССОВЫХ ПРАЗДНИКОВ В 1920-е гг. (НА МАТЕРИАЛАХ СТАВРОПОЛЬЯ)
}

В статье освещены особенности становления системы советских массовых праздников. После свержения самодержавия в феврале 1917 г. все политические силы старались обеспечить себе поддержку населения. Важным инструментарием этого были массовые мероприятия: праздники, митинги, демонстрации. Одержав победу в Гражданской войне, большевики стали выстраивать новую культурную политику. Новые праздники, памятные дни и ритуалы основывались на событиях недавней истории, преимущественно на революции 1917 года в России и рассказах о ее героях.

Основным праздником был 7 ноября - день прихода большевиков к власти (Великая Октябрьская социалистическая революция). В статье отмечено, что несколько лет отмечались также 12 марта - День свержения самодержавия в России и 18 марта - День Парижской коммуны. Также важными праздниками были Первое Мая (День солидарности трудящихся), 23 февраля (День создания Красной армии), 8 марта (Международный день работниц) и ежемесячные субботники.

Проведение всех праздников в столице и регионах строго контролировалось правящей партией. Приведенные в статье примеры показывают однотипность многих проводившихся торжеств. Пользуясь научной методикой В. Я. Проппа, в статье выделены основные структурные элементы советских праздников тех лет: демонстрации, митинги, массовые гуляния, театрализованные представления. Новой чертой массовых праздников стали общественно-политические заседания.

Показано, что в Советской России и СССР праздники были симбиозом науки, пропаганды и литературы. Для правильного написания праздничных сценариев печатались специальные методические рекомендации. Региональные авторы, как правило, пользовались опубликованными историческими источниками и старались их литературно оформить. Отмечено, что к процессу подготовки праздничных мероприятий вовлекалось большое количество советских граждан. Еще больше их участвовало в непосредственном их проведении, что и составляло одну из целей новой культурной политики большевиков.

Ключевые слова: советские праздники, российская революция 1917 года, Ставропольский край, Первое мая, 7 ноября, В. И. Ленин, свержение самодержавия, демонстрации.

\section{FORMATION OF THE SYSTEM OF SOVIET MASS HOLIDAYS IN THE 1920 s (ON THE MATERIALS OF STAVROPOL KRAI)}

The article highlights the features of the formation of the system of Soviet mass holidays. After the overthrow of the autocracy (Emperor Nicholas II) in February 1917, all political forces tried to secure the support of the population An important tool of this was mass events: holidays, rallies demonstrations. Having won a victory in Civil war, Bolsheviks began to build new cultural policy. New holidays, memorable days and rituals were based on events of recent history, mainly on the Revolution of 1917 in Russia and stories about her heroes.

The main holiday was November 7 - the day of the Bolsheviks coming to power (the Great October socialist revolution). The article notes that several years were also celebrated on March 12 - the Day of the overthrow of the autocracy in Russia and March 18 - the Day of the Paris Commune, the First of May (Day of Solidarity of Workers, May Day), February 23 (Day of the Red Army), March 8 (International Day of Workwomen) and monthly community workdays were also important holidays.

Organization of all holidays in the capital and regions was strictly controlled by the ruling party. The examples given in the article show the uniformity of many celebrations. With the reference to the scientific methodology V. Ya. Propp, the article highlights the main structural elements of the Soviet holidays of those years: demonstrations, rallies, mass celebrations, theatrical performances. A new feature of the mass holidays were social and political meetings.

It is shown that in Soviet Russia and the USSR holidays were a symbiosis of science, propoganda and literature. Special methodical recommendations how to write festive scenarios were developed. Regional authors, as a rule, used published historical sources and tried to make them literary. It is noted that a large number of the Soviet citizens was involved in the preparation process of festive actions. Even more of them participated in their direct implementation, which was one of the goals of the new cultural policy of the Bolsheviks.

Key words: soviet holidays, Russian Revolution of 1917, Stavropol Krai, May Day, holiday of November 7th, V.I. Lenin, overthrow of autocracy, demonstrations. 
Массовые праздники являлись неотъемлемой чертой жизни советских граждан с 1918 по 1991 гг Они представляли собой систему особых действий, наполненных идеологией и отмеченные значительным числом участников. Это была важнейшая черта новой культурной политики большевиков. По мнению немецкого исследователя М. Рольфа, важнейшей чертой праздников была массовая коммуникация людей, которая превращала официальное мероприятие в живое культурное событие [23, с. 10].

В исследовательской литературе, посвящённой советским праздникам, приведены неоднократные сведения о локальной специфике данной системы. М. Рольфом описаны Воронежская и Новосибирская области, Западно-Сибирский край (Кемерово) [23], М. К. Декановой - Среднее Поволжье (Самарская, Симбирская, Пензенская, Саратовская области) [8], С. Ю. Малышевой - Казань и Татарстан [17], К. В. Годуновым - Петрозаводск, Витебск [6]. Практически в каждой работе анализируются данные о праздниках, проходивших в Москве и Петрограде (Ленинграде) [14; 24]. Это объясняется не только доступностью материалов, но и спецификой новой системы праздников, строго централизованной, где к концу 1920-х гг практически не было места местным импровизациям.

Безусловно, имеется множество теоретических работ об общем значении праздников в социокультурной жизни людей, о символике и скрытых смыслах, о преемственности и новизне. Д. М. Генкин и А. И. Мазаев обосновали утверждение о насыщенных эмоциональных переживаниях, вызываемых праздниками, что давало прекрасный инструмент советской власти для ведения агитации и пропаганды [5; 17]. Классическими трудами о природе праздников и их роли в жизни народа являются труды В. Я. Проппа и М. М. Бахтина [22; 3].

Поэтому целью данной статьи является описание процесс становления централизованной советской системы праздников на региональном материале (Ставрополье). Именно примеры конкретных локальных сообществ данного исторического отрезка времени дают понимание функционирования возникшей государственной системы и ее воздействия на отдельных граждан. Пользуясь методологией В. Я. Проппа, будет дана попытка анализа структуры праздников, вычленения его отдельных элементов, которые повторялись практически в каждом календарном случае [22, с. 22].

Устанавливаемая с 1917 г. система праздников опиралась на события революции 1917 г. и Гражданской войны, на память о революционных деятелях предыдущих эпох. Основой каждого торжества становились конкретные события в истории: 23 февраля - день создания Красной армии, 18 марта - день Парижской коммуны, 6 июля - день принятия конституции СССР, 7 ноября - Октябрьская революция. К дням рождения или смерти знаменитых людей (К. Маркс, В. И. Ленин), крупным событиям (съездам партии и Советов) привязывались еще и различные ритуалы. Одним из важнейших ежемесячных ритуалов стали суб- ботники, начавшиеся в 1919 г. как добровольный общественно-полезный труд. Их популярности способствовала брошюра В. И. Ленина «Великий почин», оценивавшая субботники как новый тип общественного труда на основе свободной и сознательной дисциплины [15, с. 13-14]. Если изначальный смысл субботников был в преодолении отсталости экономики, то практически сразу появились такие формы субботников как уборка окружающей территории, которые напоминали древние обряды очищения [22, с. 143-1 44], поскольку часто проводились весной и изначально сопровождались пением и употреблением пищи. Данный смысл субботника сохранился и по сей день, показывая долгосрочную историческую преемственность.

Советская празднично-ритуальная система была жестко централизованной. Решения принимались руководством партии и спускались в регионы без дискуссий и обсуждений. После победы в Гражданской войне данная система охватила почти всю страну. Причем какое-то время праздники по революционной и пролетарской тематике сочетались с уже устоявшимися религиозными праздниками. О них говорилось в специальной методической литературе и решениях местных органов власти. Например, в 1924 г. в Ставрополе было разрешено отмечать все основные церковные праздники. Причем принял это решение Ставропольский губернский исполнительный комитет и губернский отдел профсоюзов. Губернскому отделу труда, который организовывал и отдых рабочих, предлагалось учитывать национальные праздники народов Ставрополья $[27$, с. 128]. Эта двойственность какое-то время была распространена не только в городах, но и в селе, когда праздновали и Пасху, и Рождество, и Крещение, и День Парижской коммуны, и день Октябрьской революции $[12$, с. 158]

Исторически первым праздником классового и революционного характера был день 1 мая (День Интернационала). Легально и открыто по всей стране его впервые провели в 1917 г. Причем, благодаря несовпадению календарей и новым веяниям, он отмечался 18 апреля. В Ставрополе демонстранты, которые с 9 утра собирались на ярмарочной площади у Тифлисских ворот, с 12 часов с пением и музыкой прошли по центру города. Шли солдаты, казаки, рабочие, служащие, «трудовое мещанство», школьники. Их приветствовали члены губернского Комитета общественной безопасности, которые присоединились к организатору - совету рабочих и солдатских депутатов. Особо участники манифестации откликнулись на сообщение городского головы Н. Г. Дидрихсона о разрешении Временным правительством выбирать Городскую Думу на основе всеобщего прямого, равного и тайного голосования [1].

Одно из самых первых массовых празднований Дня 1 мая прошло в Ставрополе в 1921 г. уже после установления советской власти. Многие дома по городу украшались флагами и плакатами. Ставропольский губернский исполнительный комитет совместно с городскими советом и пар- 
тийным комитетом организовал демонстрацию в которой участвовали многие горожане и гости Ставрополя. По самому городу проводились так называемые «летучие» митинги, чтобы охватить те группы горожан, которые могли не дойти до основных мероприятий. На специальном торжественном собрании всех депутатов в центре внимания были лучшие рабочие и участники Гражданской войны. Кроме политических, были и развлекательные формы праздников - спектакли, концерты, показ кинофильмов. Причем в центральном городскому саду для широкой публики была представлена постановка о разных моментах истории Парижской коммуны [27, с. 122]

В середине 1920-х гг. каждый раз создавались специальные комиссии по подготовке Первомая, которые разрабатывали агитационную кампанию. Так, в 1926 г. было дано указание сосредоточиться на вопросах хозяйственного и политического развития Советского Союза, больше разъяснять поставленные задачи и временные экономические трудности, меньше уделять внимание борьбе с религией и обзорам о международном положении $[26$, с. 36$]$.

По общепринятому мнению, Первомай противопоставлялся Пасхе, от которой он должен был отвлечь основные внимание граждан. Даже основная форма проведения - демонстрация напоминала крестный ход [2]. Демонстрации, митинги, торжественные заседания, театрализованные постановки, массовые гуляния, украшение городов и сел - вот основные элементы практически всех советских праздников, многие из которых, безусловно, «заимствованы» из исторически сложившейся народной практики

Основной праздник нового советского государства был посвящен, конечно же, революции 1917 г Причем, некоторое время отмечалась и годовщина свержения самодержавия - 12 марта, и Октябрьская революция - 7 ноября. Любопытно обоснование даты 12 марта, данное в популярном справочнике для рабочих того времени: кризис промышленности и сельского хозяйства за три года Первой мировой войны привел к голоду и недовольству народа правительством. «Бездарность царских генералов, продажность министров и глупость царя, подчинявшегося влиянию придворных мошенников и грязного проходимца Григория Распутина - скоро привели к полной разрухе внутри страны и тяжелым поражениям на фронте» [25, c. 19-20]. Затем рабочие Петрограда 23 февраля 1917 г. вышли на улицы с требованиями «хлеба!» и свержения самодержавия. 27 февраля произошли боевые столкновения, и появились погибшие. И самодержавие пало, не найдя себе сторонниковНиколай II отрекся от престола 12 марта (27 февраля по старому стилю).

Из общепринятой схемы причин революции и стройного описания событий февраля выпадает сама дата отречения монарха. Не совсем понятно, что имели ввиду авторы-составители, поскольку император подписал свой многострадальный манифест 2 марта - 15-го по новому стилю. Однако именно 12 марта в 1920-е гг. было в Советской России, а потом и в СССР официальным нерабочим днем. Если посмотреть другие справочники, то выбранная дата становится более или менее понятной: это «начало Февральской революции. Образование Петербургского Совета Рабочих депутатов» [13, с. 12]. В научно-популярном политическом словаре, выпущенном в 1924 г., статья про Февральскую революцию очень похожа на объяснение праздника в справочнике рабочего: «27 февраля (12 марта) рабочие Питера совместно с солдатами низвергли самодержавие и для защиты своих интересов образовали Советы Рабочих и Солдатских депутатов. Вскоре вся страна покрылась Советами Рабочих, Солдатских и Крестьянских Депутатов. Буржуазия образовала Комитет Государственной Думы, а затем попыталась приспособить революцию к своим интересам, захватив в свои руки Временное Правительство, проводившее при поддержке социал-соглашательских партий буржуазную политику, направленную против интересов рабоче-крестьянских масс. День 12 марта празднуется как день свержения самодержавия» [21, c. 348].

Соответственно в этом же словаре все остальные события 1917 года описываются в статье «Октябрьская революция» [21, с. 221-223]. Дается краткая хроника, отмечаются апрельский, июньский июльский кризисы и корниловский мятеж, расстановка политических сил и борьба в октябре-ноябре 1917 г. из большевиков названы фамилии только Ленина и Троцкого. Принцип отбора слов для словаря был прост: к первому изданию в 1922 г. было просмотрено около 500 номеров московских и петербургских газет, выписаны сложные слова из статей, составлены их объяснения «для среднего читателя: рабочего, красноармейца, учителя, студента, слушателя совпартшколы. В словаре общее предпочиталось специальному, а из специального бралось только то, что поступило в обиход нашей речи и общей печати» $[21$, с. 6]. Если такой словарь доходил до деревни, то он, конечно, комментировался и становился еще более упрощённым.

Праздник 12 марта отмечался уже в 1919 г. массовыми мероприятиями. Правда происходило это только в Петрограде. В Народном доме было проведено игрище о Февральской революции «Свержение самодержавия». В изданном в 1926 г. обзоре массовых празднеств в Ленинграде праздник 1919 г. отмечен особо: авторы назвали замечательным и состав участников - красноармейцы из казарм, и метод создания текста - импровизация, и драматургическое и сценическое построение обрядово-бытовой принцип манифестации и митинга [18, с. 57]. На двух площадках, соединенных деревянными мостками, исполнялись различные сцены без декораций и с минимальным набором костюмов. Главными сюжетными единицами стали Манифестация «к Дворцу» с пением «Спаси господи» и заключительная штыковая атака на него же. Диалоги перемежались песнями, митинговым массовым говором, криками, спорами. Такое действие разыграли много раз в казармах, лагерях, 
на лестницах зданий, на Дворцовой площади. Затем игрище стало основой для подобной постановки в дни празднования Октября $[18$, с. 58]. В 1920-1921 гг. даже в Петрограде перестали ставить масштабные постановки на день Свержения самодержавия, который оставался какое-то время просто новым важным праздником.

Например, в том же 1926 г. многочисленные мероприятия прошли в Пятигорске. В газете «Терек» так писали об этом дне: «Море яркого и радостного солнечного света, наполнившего все уголки и мгновенья весеннего утра, и величавая тишина пробуждения сил природы дню 12 марта придали характер массового праздника - воспоминания о низвержении самодержавия» [28].

Торжественные заседания в честь 9-й годовщины февральской революции были проведены союзами печатников, металлистов, пищевиков, строителей, работников искусств, просвещения, коммунальников, медиков и санитаров, советских торговых служащих. Также разные торжества были в школах, а детские утренники были перенесены на 18 марта. На некоторых собраниях, которые стали вечерами воспоминаний, выступили члены общества политкаторжан и ссыльнопоселенцев И. Г. Горбштейн и М. С. Киселев, которые по два года провели во владикавказской тюрьме, а затем и несколько лет в ссылке $[20$, с. 128,238$]$.

Последний раз речь о важной исторической дате 12 марта как о массовом празднике - дне свержения самодержавия - шла именно в 1926 г Затем, в 1927 г. этот праздник исчез, акцент был перенесен на юбилейное празднование Октябрьской революции. Уменьшение форм (элементов) праздника свидетельствует об уменьшении значимости праздника и скорой его исчезновении из жизни граждан. В последний год существования праздника свержения самодержавия остался только один, и тот весьма формальный, элемент торжественное заседание, сопряженное с воспоминаниями участников революции. Заседание как элемент праздника возникло в жизни народа относительно недавно, и поэтому сам праздник легко исчез из сознания и практики советских граждан.

На Ставрополье, как и других регионах, была своя специфика празднования главного праздника. В условиях Гражданской войны, когда не вся Ставропольская губерния была подконтрольна советской власти, Таманская армия, захватившая Ставрополь в октябре 1918 г., способствовала временному восстановление советских и партийных органов и празднованию первой годовщины Октябрьской революции. По распоряжению российского СНК для празднования выделялось по 10 рублей на каждого красноармейца, но «деньги эти на руки выданы быть не должны, а обращены на просветительные и увеселительные цели, а также на улучшение питания в день праздника» [7, с. 189]. Губисполком создал специальную комиссию, решением которой празднества отмечались устроением лекций, манифестаций и спектаклей.
В Ставрополе город украсили красными флагами и транспарантами, цветной электрической иллюминацией. «7 ноября местные коммунисты (их оказалось полсотни) надели нарукавные красные повязки и вместе с рабочими Форштадта приняли участие в первой октябрьской демонстрации» [9]. В книге Ф. Головенченко и Ф. Емельянова, изданной в 1928 г., уточнялось, что городским Советом для праздника были заказаны «2 флага - для Совета и для Компартии и 100 лент: 50 - для членов Совета и 50 - для членов партии» [7, с. 172]. На площади Ленина состоялся воинский парад. Весь день шли массовые народные гулянья. «На площадях, бульварах, в роще шли лихие казачьи пляски, распевались революционные песни. Ни угроза полного окружения города белогвардейцами, ни тяжелая эпидемия сыпняка и «испанки», ни недостаток боеприпасов, ни рано наступившие осенние холоде, ни постоянные остервенелые атаки лучших полков “добровольческой армии) не смогли затмить огромной радости, захлестнувшей в тот день сердца бойцов таманцев» [9].

В Пятигорске были украшены дома в центре и курортные трамвайчики, вечером зажглись огни иллюминации. 6 ноября 1918 г. в Народном доме, Лермонтовской галерее, центральной гостинице и мужской гимназии проходили торжественные собрания. Печатались и распространялись агитационные листовки, написанные местным большевиком Г Анджиевским: «Празднуйте же эту великую годовщину с красными знаменами, с цветами, с пением ваших гимнов и с сознанием того, что победа за вами! Спешите принять участие в триумфальном шествии народа-победителя! Стихийный пожар мировой революции озаряет все уголки земного шара! Через знание, труд и борьбу - спешите к Октябрьской победе! Да здравствуют завоевания Великой Октябрьской революции» [9]. 7 ноября прошел массовый митинг на площади около вокзала, которую в честь праздника переименовали в площадь Октябрьской революции, и военный парад, который принимал председатель Реввоенсовета Северо-Кавказской республики Я. Полуян. Также в программе были бесплатные киносеансы, концерты, летучие митинги. В народном доме показали революционную пьесу «Зори» Эмиля Верхарна. Завершилось празднование первой годовщины Октябрьской революции в Пятигорске фейерверком.

Уже в первую годовщину абсолютно нового праздника можно увидеть достаточно серьезный вклад народных масс не только в гуляния, но и в организацию торжеств. Здесь присутствуют те же элементы праздника, некоторые из которых возникали по достаточно импровизационно: партийные заседания, военный парад, митинги, концерты, киносеансы, спектакли. Затем народная инициатива войдет в то русло, которое им будут определять партийные органы. Ориентировка на массовость участия и большое количество мероприятий, по мнению М. Рольфа, уходят корнями частично в дореволюционную праздничную традицию, но, в основном, в революционный 1917 г $[23$, c. $42-62]$. После падения самодержавия ка- 
ждая политическая сила, каждая партия считала что праздничные демонстрации и торжественные уличные шествия служат укреплению их авторитета. Многочисленные митинги, демонстрации, шествия, сходки в крупных городах и провинции в 1917 г. ориентировались на массовость и уличную политику.

Однако, в другом М. Рольф несколько преувеличил, однозначно связав праздники в провинции и грабежи винных лавок и спиртзаводов. «Революция происходила там в форме пьяных эксцессов и погромов; за коллективной попойкой следовали коллективные акты насилия, жертвами которых становились символы, учреждения и лица, хоть в чем-то воплощавшие собой порядок» [23, с. 63]. Не подвергая сомнению данные о многочисленных грабежах, случавшихся в том числе и на Ставрополье, следует отметить отсутствие прямой зависимости между праздниками и следовавшим после пьяных разгулов насилием. Если это касалось только 1917 г., то природа грабежей не носила «праздничного» характера. Это был бунт против действительности, действующей власти, инфляции, продуктового кризиса.

Скорее всего, М. Рольф ориентировался на отрывок, приведенный В. П. Булдаковым в своем известном труде «Красная смута»: «В праздник деревня отправлялась в церковь, а после обедни всем миров грабила соседние усадьбы» [4 c. 197], описанный митрополитом Евлогием применительно к Волыни на Украине. В своих воспоминаниях Евлогий не говорит о систематическом пьянстве в праздники, отмечая нарастание общей волны насилия с лета 1917 г:: «Общее положение в епархии становилось все хуже и хуже. В деревнях грабежи и разбой, в уездах погромы помещичьих усадеб и убийства помещиков. Случалось что в праздник деревня отправлялась в церковь а после обедни всем миром грабила соседние усадьбы. Престарелый князь Сапега, известный на всю округу благотворитель, человек культурный и доброжелательный, вышел к крестьянам и хотел вступить с ними в переговоры, но какой-то солдат крикнул: «Да что его!...) - и убил на месте. Почуяв кровь, толпа озверела и разгромила его усадьбу. Особенно неистовствовали в прифронтовой полосе. Тут была просто вакханалия. И немудрено! Все вооружены, все на войне привыкли к тому, что человеческая жизнь ничего не стоит.. Куда девалось «Христолюбивое воинство» кроткие, готовые на самопожертвование солдаты? Такую внезапную перемену понять трудно: не то это было влияние массового гипноза, не то душами овладели темные силы...» [10]. Сам В. П. Булдаков называет крестьянские грабежи «волнами вторичного насилия, передаваемого общественной системе представителями уродливо урбанизирующегося поколения, чье возрастное самоутверждение пришлось на пик мужицкого разбоя» $[4$, с. 198$]$.

Возвращаясь к праздникам заметим, что с каждым годом торжества к дню Октябрьской революции сопровождалось все большим количеством разнообразных мероприятий. Услож- ненная структура и массовость, карнавальные и театральные элементы требовали продуманных сценариев, на которые в провинции не всегда находились творческие силы и способности. Для помощи в организации представлений выходили специальные методические пособия и сборники. В одном из них, выпущенном в 1924 г. были довольно подробные методические рекомендации для создания различных сценариев. Культпросвет работнику рекомендовалось отбирать материал для праздника исходя из двух критериев: «идейная, политико-воспитательная значительность и художественная действенность» [19, с. 8]. По мнению авторов сборника, почти все материалы о революции привлекательны в силу мировой значительности события. Даже простые телефонные переговоры В.И. Ленина, которые в обычном спектакле не используются, для постановки во время праздника подходят хорошо, так как характеризуют важный исторический момент и фигуру вождя пролетариата

Содержательно из всех материалов можно выделить 4 темы: 1) сравнение между положением рабочих до и после Октября, 2) «самый момент Октября 1917 г., картины восстания, обстановка, борьба, трудности, враги, друзья, вожди», 3) «борьба за сохранение завоеваний Октября, гражданская война», нэп, 4) достижения на текущий момент времени $[19$, с. 8-9]. Все доступные исторические материалы делились также на 4 вида, к каждому из которых давались свои рекомендации. Для театрализации какого-то исторического момента следовало определиться с местом и временем произошедшего события, развитием сюжета, сочинением драматического текста. В качестве пространственной точки авторы рекомендовали взять место сосредоточения появляющихся новостей: Смольный, телеграф, улицу, проходной двор, фабрику. Это позволило составить представление близким по духу к описываемым событиям. После этого определяем получаемые известия в виде сообщений, приказов, лозунгов, «характерных для переворота, а может быть и подлинных. Они и пропитывают представление необходимым театральным действием» [19, с. 11]. Смена действующих лиц, обмен сообщениями, постоянные звуковой фон из-за кулис (стрельба, шум голосов, маршировка, пение), диалоги - вот элементы сценария, рекомендованные для постоянной подпитки напряжения, «характерного для Октябрьских событий».

Для написания реплик, лозунгов и сообщений, членам художественного кружка предлагалось «на минуту представить себя действующими лицами представления, к которым приходят какие-то сообщения о ходе событий. Ответ, слова находятся сами собой». Например, в ответ на сообщение о подходе войска под руководством Керенского к Петрограду от действующих лиц могут быть такие ответы: «Предатели революции», «Отстоим наше дело», «Нужно сплотиться», «Нужно сообщить в Военно-революционный комитет», «Товарищи, к оружию». В качестве самих сообщений можно взять подлинные документы того времени без 
каких-либо изменений. Авторы рекомендовали для этого книгу Д. Рида «Десять дней, которые потрясли мир» или воспоминания Троцкого, Антонова-Овсеенко. При этом не надо было перегружать представление текстом, давая больше действия. В достаточно коротком представлении, еще и ограниченном только сценой необходимо дать почувствовать зрителю «огромное массовое движение, борьбу, временные поражения, подьем, героизм, препятствия и победу» [19, с. 12].

Отдельно стоит сказать о рекомендациях в театрализованных праздничных действиях по использованию подлинных исторических документов. Сохранившиеся телеграфнные и телефонные переговоры смело могли стать частью постановки практически без изменений. Другие документы могли тоже полностью включаться в действие, поскольку «стиль и язык их, почти всегда вызывающий в нашей памяти время, к которому документ относится, способен больше всяких других приемов сделать произведение живым, реальным, значительным и характерным» [19, c. 15]. Это «вызовет в зрителе впечатление подлинности, которое с большим трудом иногда удается даже большому художнику-мастеру».

Фактически в данных рекомендациях описывается процесс творчества через определённые, уже закреплённые в сознании образы и картины революции. Названы узловые моменты действия, которые потом будут встречаться в и пьесах, и в прозе, и в поэзии. Так, у А. Веселого в его главном романе «Россия, кровью умытая» все элементы революционного саспенса на Юге России присутствуют в полной мере: есть и массовость, и подвиги отдельных героев, противодействие анархии со стороны новой власти. В «Железном потоке» А. С. Серафимовича «впечатляюще показаны огромные трудности похода полураздетых, голодных бойцов 1-й колонны, их боевые схватки с врагом, в ходе которых росли политическая сознательность и организованность, укреплялась воинская дисциплина и, как следствие этого, боеспособность частей, беспрерывно громивших и отбрасывавших со своего пути войска белых генералов» [11, с. 57]. Фактически любое литературное произведение того времени о революции и Гражданской войне следовало предложенной драматической структуре.

Рекомендации к написанию сценариев для праздничных театральных постановок органич- но укладываются в схему взаимодействия науки-пропаганды-литературы того периода. Для достоверности использовались настоящие документы или воспоминания действующих лиц, которые активно собирались Исптартом и публиковались в исторических, общественно-политических и публицистических журналах. Для идеологического воздействия авторы рекомендаций требовали не усложнять текст и ввести в него короткие отрывки - лозунги или диалоги, а драматизм написанной сценки должен был достигаться путем постоянного нагнетания напряжения. Только в отличие от профессиональных писателей, которые сами могли создавать подобные рекомендации, над созданием маленьких новых пьес должны были работать обычные люди. Конечно, кроме просвещения и пропаганды, здесь еще заложена цель создания новой интеллигенции, нового советского человека, который сможет трудиться как у станка, так и за писательским столом. Подобная практика должна была стирать у населения некое уважение к мыслительному труду, приравнивая интеллектуалов к «пролетариям умственного труда». Длительная подготовка к подобным мероприятиям консолидировала широкие народные массы и вовлекала их в новую систему традиций.

Вывод: советские праздники в течение первого десятилетия советской власти превратились в стройную централизованную систему. Старые религиозные праздники постепенно исчезли, остались только новые, которые несли мощный идеологический и пропагандистский смысл, апеллируя к истории революции 1917 г., Гражданской войне и ряду других исторических событий. Практически к каждому празднику организовывались специальные группы для подготовки, печатались методические указания, издавались и распространялись тематические тезисы, на которые необходимо было ориентироваться при проведении митингов, демонстраций и заседаний. Структура каждого праздника включала в себя демонстрации, митинги, театральные действия, массовые гуляния. Праздники охватывали все слои населения, с каждым последующим годом вовлекая в орбиту подготовки и участия все большее количество советских граждан. Данная система во многих чертах сохранилась и в современной России, утратив свою идейно-революционную наполненность

\section{Источники и литература}

1. 1 мая в Ставрополе 1917 года // Ставрополье. 1926. №5. С. 50-51.

2. Алексеевский М. Первое мая: история и трансформация праздника. URL: https://postnauka.ru/faq/64151 (Дата обращения: 29.01.2019)

3. Бахтин М. М. Творчество Франсуа Рабле и народная культура средневековья и Ренессанса. М.: Художественная литература, 1990. 541 с.

4. Булдаков В. П. Красная смута. Природа и последствия революционного насилия. М.: РОССПЭН, 2010. 965 с

5. Генкин Д. М. Массовые праздники. М.: Просвещение, 1975. 140 с

6. Годунов К. В. Первая годовщина Октября: «старое» и «новое» в советской праздничной культуре. URL: http:// www.polithistory.ru/upload/iblock/a51/a51 be20953936ce14836b428beed7546.pdf (Дата обращения: 15.01.2019)

7. Головенченко Ф., Емельянов Ф. Гражданская война в Ставропольской губернии. Ставрополь: Пролетарий, 1928 $221 \mathrm{c}$ 
8. Деканова М. К. Трансформация российской праздничной культуры в конце XIX - первой трети XX в.: центр и провинция: дисс. ... канд. исторических наук. Самара, 2009. 244 с.

9. Доценко А. Выросли мы в пламени... Празднование первой годовщины Октября на Ставрополье // Ставропольская Правда. 1962. 7 ноября. №264. С. 3.

10. Евлогий (Георгиевский). Путь моей жизни. URL: https://azbyka.ru/fiction/put-moej-zhizni/2/\#n16 (Дата обращения: 14.06.2018).

11. Ефимов Н. А. Историческая основа «Железного потока» А. С. Серафимовича // История СССР. 1978. №4. С. 55-72.

12. Казачество в истории Ставрополья: книга для чтения для учащихся 8-9 классов / Невская Т. А., Покотилова Т. Е. и др. Издательство «Лепта Книга»; Гуманитарный изд. центр ВЛАДОС, 2015. 223 с.

13. Красный календарь Закавказья: на армянском, грузинском, русском и тюркском языках. Б.м. Агентство «Связь», 1925. 122 c

14. Кустова Э. М. Советский праздник 1920-х годов в поисках масс и зрелищ // Неприкосновенный запас. 2015. №3 (101). URL: https://www.nlobooks.ru/magazines/neprikosnovennyy_zapas/101_nz_3_2015/article/11509/ (Дата обращения: 02.02.2019).

15. Ленин В. И. Полное собрание сочинений. 5-е изд. Т. 39.

16. Мазаев А. И. Праздник как социально-художественное явление. М.: Наука, 1978. 398 с.

17. Малышева С. Ю. Советская праздничная культура в провинции: пространство, символы, исторические мифы (1917-1927). Казань, Рутен, 2005. 400 с.

18. Массовые празднества. Л.: Academia. 1926. 206 с

19. Октябрь. (Сборник пособий для проведения праздника октябрьской годовщины в рабочих клубах) / под ред. Е. П. Шалагиновой. М.: Красная Новь, 1924. 170 с.

20. Политическая каторга и ссылка: Биографический справочник членов общества политкаторжан и ссыльно-поселенцев. М.: Всесоюз. о-во полит. каторжан и ссыльно-поселенцев, 1929. 686 с.

21. Политический словарь: краткое научно-популярное толкование слов / под общей редакцией Б. М. Эльцина. М., Л., Красная Новь, 1924. 400 с.

22. Пропп В. Я. Русские аграрные праздники. Спб.: Терра, 1995. $176 \mathrm{c}$

23. Рольф М. Советские массовые праздники. М.: РОССПЭН, 2009. 439 с.

24. Свиридова Е. Г. Государственная политика СССР в сфере праздничной культуры (20-40-е гг.) // Время науки. 2014. Вып. 2. С. 24-33.

25. Справочник рабочего: бесплатное приложение к «Рабочей газете». М., 1924. 254 с

26. Ставрополье. 1926. №4.

27. Ставропольская городская Дума. 200 лет. Историческая хроника. М.: «Воскресенье», 2008. 384 с.

28. Терек. 1926. 12 марта. №59. С. 4.

\section{References}

1. 1 Maya v Stavropole 1917 goda (May Day in Stavropol, 1917) // Stavropolye (magazine).1926. No. 5. P. 50-51. (In Russian)

2. Alekseevskiy M. Pervoye maya: istoriya i transformaziya prazdnika (May Day: History and Transformation of the Holiday) // URL: https://postnauka.ru/faq/64151 (Accessed: 29.01.2019) (In Russian)

3. Bahtin M. M. Tvorchestvo Francois Rabelais I narodnaya kul'tura srednevekov'ya I Renessansa. (Francois Rabelais's Works and Folk Culture of the Middle Ages and the Renaissance). Moscow: Hudozhestvennaya literature, 1990. 541 p. (In Russian)

4. Buldakov V. P. Krasnaya smuta. Priroda I posledstviya revolyuzionnogo nasiliya. (Red Distemper. The Nature and Consequences of Revolutionary Violence). Moscow: ROSSPEN, 2010. 965 p. (In Russian)

5. Genkin D. M. Massovye prazdniki. (Mass Holidays). Moscow: Prosveschenie. 1975. 140 p. (In Russian)

6. Godunov K. V. Pervaya godovschina Oktyabrya: «staroe» i «novoe» v sovetskoy prazdnichnoy kul'ture (The First Anniversary of October: the "Old» and "New» in the Soviet Festive Culture). URL: http://www.polithistory.ru/upload/iblock/ a51/a51 be20953936ce14836b428beed7546.pdf (Accessed: 15.01.2019) (In Russian)

7. Golovenchenko F., Emel'yanov F. Grazhdanskaya voyna v Stavropol'skoy gubernii. (Civil War in the Stavropol Province). Stavropol: Proletariy, 1928. 221 p. (In Russian)

8. Dekanova M. K. Transformaziya rossijskoj prazdnichnoy kul'tury v konce XIX - pervoy treti XX v.: centr i provinciya (Transformation of the Russian Festive Culture at the end of the XIX - the First Third of the XX Century: the Center and the Province): thesis. Samara, 2009. 244 p. (In Russian)

9. Docenko A. Vyrosli my v plameni... Prazdnovanie pervoy godovshchiny Oktyabrya na Stavropol'e. (We Grew up in a Flame ... The Celebration of the First Anniversary of October in the Stavropol Region) // Stavropol'skaya Pravda. 1962. November 7. No. 264. p. 3. (In Russian)

10. Evlogiy (Georgievskiy). Put' moey zhizni. (Way of My Life) URL: https://azbyka.ru/fiction/put-moej-zhizni/2/\#n16 (Accessed: 14.06.2018) (In Russian)

11. Efimov N. A. Istoricheskaya osnova "Zheleznogo potoka» A. S. Serafimovicha (The historical Basis of the "Iron stream" of A.S. Serafimovich) // Istoriya SSSR, 1978. No. 4. P.55-72. (In Russian)

12. Kazachestvo v istorii Stavropol'ya (Cossacks in the History of Stavropol Krai): kniga dlya chteniya dlya uchashchihsya 8-9 klassov / Nevskaya T. A., Pokotilova T. E. i dr. Izdatel'stvo "Lepta Kniga»; Gumanitarnyy izd. centr VLADOS, 2015. 223 p. (In Russian)

13. Krasnyy kalendar' Zakavkaz'ya: na armyanskom, gruzinskom, russkom i tyurkskom yazykah. (Red Calendar of Transcaucasia: in the Armenian, Georgian, Russian and Turkic Languages) B.m. Agentstvo "Svyaz'», 1925.122 p. (In Russian) 
14. Kustova E. M. Sovetskiy prazdnik 1920-h godov v poiskah mass i zrelishch (The Soviet Holiday of the 1920 s in Search of the Masses and Shows) // Neprikosnovennyy zapas URL: https:/www.nlobooks.ru/magazines/neprikosnovennyy_ zapas/101_nz_3_2015/article/11509/ (Accessed: 02.02.2019) (In Russian)

15. Lenin V. I. PSS (Complete works). Fifth edition. Vol. 39. (In Russian)

16. Mazaev A. I. Prazdnik kak social'no-hudozhestvennoe yavlenie. (Holiday as a Social and Art Phenomenon) Moscow: Nauka 1978. 392 p. (In Russian)

17. Malysheva S. Yu. Sovetskaya prazdnichnaya kul'tura v provincii: prostranstvo, simvoly, istoricheskie mify (The Soviet Festive Culture in the Province: Space, Symbols, Historical Myths) (1917-1927). Kazan', Ruten 2005.400 p. (In Russian)

18. Massovye prazdnestva (Mass Festivals). Leningrad: Academia, 1926. $206 \mathrm{p}$

19. Oktyabr'. (Sbornik posobiy dlya provedeniya prazdnika oktyabr'skoy godovshchiny $\mathrm{v}$ rabochih klubah) / ed by E. P. Shalaginovoy (October. A Collection of Manuals for the Celebration of the Anniversary of the October in the Working Clubs). Moscow: Krasnaya Nov', 1924. 170 p. (In Russian)

20. Politicheskaya katorga i ssylka: Biograficheskiy spravochnik chlenov obshchestva politkatorzhan i ssyl'no-poselencev. (Political Hard Labor and Exile: Biographical Directory of Members of the Society of Political Prisoners and Exiled Settlers) Moscow: All-union society political convicts and exiles, 1929. 686 p. (In Russian)

21. Politicheskiy slovar' (Political Dictionary) / ed by B.M. EHl'cina. Moscow, Leningrad, Krasnaya Nov'. 1924.400 p. (In Russian)

22. Propp V. Ya. Russkie agrarnye prazdniki. (Russian Agrarian Holidays). St.Petersburg, Terra, 1995.176 p. (In Russian)

23. Rolf M. Sovetskie massovye prazdniki (Das sovietische Massenfest). Moscow: ROSSPEN, 2009.439 p. (In Russian)

24. Sviridova E. G. Gosudarstvennaya politika SSSR v sfere prazdnichnoy kul'tury (20-40-e gg.) (State Policy of the USSR in the Sphere of Festive Culture (the 20-40s) // Vremya nauki. 2014. Vol. 2. P. 24 - 33. (In Russian)

25. Spravochnik rabochego: besplatnoe prilozhenie k «Rabochey gazete» (Reference Book of the Worker). Moscow, 1924. 254 p. (In Russian)

26. Stavropolye (magazine). 1926. No. 4. (In Russian)

27. Stavropol'skaya gorodskaya Duma. 200 let. Istoricheskaya hronika. (Stavropol City Duma. 200 years. Historical Chronicle). Moscow: "Voskresen'e», 2008. 384 p.

28. Terek (newspaper). 1926. March 12. No. 59. P.4. (In Russian)

\section{Сведения об авторе}

Оборский Евгений Юрьевич - кандидат исторических наук, доцент кафедры истории России гуманитарного института Северо-Кавказского федерального университета (Ставрополь) / oborskye@ gmail.com

\section{Information about the author}

Oborskii Evgenii - PhD in Historical Sciences, Associate Professor of Chair of Russian History of Institute of Humanities of North Caucasus Federal University (Stavropol) / oborskye@gmail.com 